\title{
Trajetória da Educação: da Cultura Clássica às Reflexões sobre a Contemporaneidade Escolar
}

\author{
Carmen Lucia Fornari Diez ${ }^{1}$ \\ Vanice dos Santos ${ }^{2}$ \\ Isabel Nercolini Ceron ${ }^{3}$
}

\begin{abstract}
RESUMO
Este artigo tem como objetivo fazer uma reflexão sobre a escola, partindo da Grécia clássica, olhando outros tempos históricos e suas influências na contemporaneidade com base em autores como Ariès (1981), Carvalho (2014), Châtelet (1994), Comenius (2006), Donzelot (1980), Dussel (2017), entre outros. Embasado no pensamento e filosofia de Michel Foucault (2012; 2016), podemos refletir e buscar meios de escapar do determinismo histórico, suscitando o questionamento às autoridades, às referências sociais e às organizações que estão estabelecidas de modo a denunciar as imposições e as formas de exclusão, com vistas à possibilidade de cogitar transformar a escola contemporânea em espaço dinâmico. A instituição escolar precisa pensar e repensar estratégias visando modificações nas relações de forças, numa arte de desgovernar, desinstitucionalizando-se em um movimento de contra poder, considerando os sujeitos que nela estão inseridos.
\end{abstract}

PALAVRAS-CHAVE: Educação. História da Educação. Escola.

Educational Trajectory: From Classical Culture to Reflections on School Contemporaryty

\footnotetext{
${ }^{1}$ Pós-doutora em Filosofia pela Universidade Carlos III de Madrid. Professora Associada da Universidade Federal do Paraná (UFPR), Paraná, PR, Brasil. https://orcid.org/0000-0002-5341-5213.miuxe@ hotmail.com.

2 Doutora em Educação (UFRGS). Docente pesquisadora no Programa de Pós-Graduação em Educação da Universidade do Planalto Catarinense (PPGE/UNIPLAC), Lages, Santa Catarina, Brasil. https://orcid.org/0000-00024852-5311.profa.vanice@uniplaclages.edu.br.

${ }^{3}$ Mestre em Educação (UNIPLAC). Professora de Educação Infantil pela Secretaria Municipal de Educação de Lages, Santa Catarina, Brasil. https://orcid.org/0000-0001-5345-096X. isabelnceron@gmail.com.
} 


\begin{abstract}
This article aims to make a reflection on the school, starting from classical Greece, looking at other historical times and their influences in the contemporaneity based on authors suck as Ariès (1981), Carvalho (2014), Châtelet (1994), Comenius (2006), Donzelot (1980), Dussel (2017) among others. Based on the thinking and philosophy of Michel Foucault (2012; 2016), we can reflect on and seek ways to escape from historical determinismo, raising questions about authorities, social references and organizations that are established in order to denounce the impositions and the forms of exclusion, with a view to the possibility of considering to transform the contemporary school into a dynamic space. The school institution must think and rethink strategies aimed at changes in the relations of forces, in an art of misgovernment, deinstitutionalizing itself in a movement of conter power, considering the subjects that are inserted in it.
\end{abstract}

KEYWORDS: Education. History of Education. School.

\title{
Introdução
}

Abordar a trajetória da educação implica reconhecer que o ser humano e as civilizações trazem consigo o aprendizado de suas vivências e experiências. O conhecimento histórico contribui para esclarecermos e compreendermos nossa realidade cotidiana, nossas atitudes, nossas ações e refletirmos sobre cada momento histórico que vivemos.

Assim, este artigo tem como objetivo fazer uma reflexão sobre a escola, desde a Grécia Clássica e Idade Média em direção à atualidade, a partir de dados bibliográficos, para oportunizar o conhecimento de como a escola surgiu no mundo ocidental, incluindo brevemente considerações acerca da criança. Percorreremos algumas influências na 
contemporaneidade, tendo como fio condutor o pensamento e filosofia de Michel Foucault (2012; 2016).

\section{O Pensamento Grego e a Escola na Grécia Antiga}

O marco inicial da instituição escolar é cultura clássica cujo berço foi a Grécia antiga. Após a invasão dórica atingir de forma bárbara a civilização creto-micênica - em torno do ano 1000-700 a. C. - , a civilização grega se elaborou com uma educação diferente dos tempos minóicos (MARROU, 1975).

A Grécia foi formada por jônicos, eólicos e dóricos. Os dóricos viviam ao norte da Grécia, na Macedônia e na Calcídica. Quando se deslocaram para o Peloponeso, foram considerados bárbaros, por isto invasores, gerando a época chamada de Idade das Trevas. Este estigma se consolidou, não obstante estes povos possuíssem conhecimentos importantes, como a metalurgia do ferro, mas porque não tinham nenhum sistema de escrita. Para Hall (2001, p. 8):

A palavra 'bárbaros' - tanto o adjetivo quanto o substantive registrada apenas ocasionalmente antes da invasão, entra agora no uso comum para designar não apenas os persas mas todos os outros grupos de não-gregos, sem qualquer diferenciação. $\mathrm{Na}$ tragédia e na comédia grega, os personagens bárbaros assumem um papel mais central e são em geral representados como cruéis, sem moderação, covardes, servis e afeminados.

A história da cultura clássica grega se fez a partir de Homero com seus poemas heroicos Ilíada e Odisseia, documentos que trazem elementos de mil anos de história e alguns detalhes referentes ao tempo minoano ${ }^{4}$.

\footnotetext{
${ }^{4}$ Trata-se, do período histórico da Grécia, do ápice da cultura minóica em Creta. Segundo Marrou (1975), o tempo anterior à barbárie dórica modificou a civilização creto-micênica (MARROU, 1975).
} 
O mundo mediterrâneo na Antiguidade teve uma educação clássica, por meio de um sistema de educação coerente e determinado (MARROU, 1975). Por volta do século X a IV antes de Cristo na história ocidental era possível verificar a existência da educação clássica, desde seu início e sua maduração, se estendendo no período helenístico e se extinguindo com as invasões bárbaras e o desaparecimento do Império (MARROU, 1975).

Desde a Grécia Antiga, a trajetória da razão conversa com a educação em questões relativas à produção, constituição e transmissão dos saberes. A filosofia contribuiu para as transformações da sociedade durante as gerações, principalmente em relação ao desenvolvimento e fundamentação da razão, bem como do pensamento. "A história da razão é também a história dessas reanimações sucessivas: o nascimento da democracia, a importância da palavra, a hipótese das ideias, a passagem da persuasão para a procura da verdade" (CHÂTELET, 1994, p. 13).

Foucault (2012), inicialmente com a arqueologia, considerava em seus estudos os discursos produzidos nos diferentes contextos, descrevendo a constituição dos saberes e suas relações, como apareciam e se transformavam. Na sequência, pela genealogia, o autor investigou e analisou os extradiscursos que constituem os sujeitos nas relações entre poder e saber e, na qual, as instituições têm importante papel dessa produção do sujeito. De acordo com o autor, a produção do sujeito sofre influências do modo de vida de sua época, diante de um contexto histórico, social, cultural e político. Como ele diz em As Palavras e as Coisas, cada episteme permite a produção de determinados saberes. Foucault identifica como episteme as disposições ou configurações de saber de cada época e contexto histórico. Segundo Araújo (2000, p. 56), o que Foucault chama de episteme, é similar

[...] à noção de Kuhn de paradigma; Foucault situa-se, assim, entre os epistemólogos contemporâneos de linha contextualista e pragmática: os objetos não pré-existem ao saber; eles existem como 
acontecimentos, como aquilo que uma época pôde dizer devido a certos arranjos entre o discurso e condições não discursivas.

Para Foucault (2012), imbricada à produção do conhecimento, sempre existiram mecanismos de exercício de poder, as instituições, que utilizando estratégias e técnicas de dominação, construíam saberes que produziam sujeitos de acordo com as regras e morais estabelecidas em cada contexto, em cada realidade. $\mathrm{Na}$ trajetória da razão, diferentes pontos da rede social desempenhavam micropoderes ${ }^{5}$ que exerciam o controle de gestos, atitudes, comportamentos, hábitos, discursos e verdades.

Assim, vamos nos reportar à cultura clássica para a reflexão proposta. Após o combate aos bárbaros da Pérsia pelos atenienses, a democracia de Atenas se espalhou pela Grécia, tornando-se um modelo e trazendo as técnicas e as artes na educação de sua geração. Surgiu então a "retórica", uma técnica específica da palavra que demandou uma nova profissão, a de professores capazes de ensinar a "falar bem". Estes professores da democracia eram nomeados por Platão de "sofistas" (CHÂTELET, 1994).

Sócrates e Platão não concordavam com os sofistas e sua retórica, considerando que o diálogo, como dispositivo argumentativo, traria a palavra para a reflexão, descobrindo as respostas aos questionamentos no coletivo. É a chamada arte do diálogo, ou "dialética" (CHÂTELET, 1994). Analisando as ideias destes dois filósofos, é possível compreender que compartilhamos nossas experiências na coletividade, sendo necessário levar em consideração na decisão tomada, o ponto de vista de todos, do coletivo.

Por meio de questionamentos, Sócrates construía diálogos com os presentes, considerando todas as colocações e fazendo com que todos pensassem e refletissem sobre cada item, trazendo suas ponderações durante o diálogo (PLATÃO, 1991). Oportunizava que todos colocassem seus pontos de vista, suas crenças e ideias. No movimento do diálogo, com

\footnotetext{
${ }^{5}$ Dado que este é um conceito de Michel Foucault (2012 optamos por manter a grafia utilizada pelo referido autor.
} 
postura ética, mostrava-se respeitoso diante das diversas maneiras de pensarem e, por meio do diálogo, construíam juntos os diferentes conceitos.

Jaeger (1888-1961), filólogo alemão, trouxe no início de sua obra Paidéia: a Formação do Homem Grego, um panorama dos gregos na história da educação, relacionando a Antiguidade Grega e suas influências para com a história atual da educação. O termo grego Paidéia, apresenta um significado muito mais amplo que não pode ser definido por apenas uma expressão, como cultura, ou tradição ou até mesmo educação, pois estes termos limitam apenas a explicar um aspecto do verdadeiro sentido da palavra grega (JAEGER, 2001).

Segundo Jaeger (2001), havia a concepção de que o homem é formado por uma estrutura dupla: corpórea e espiritual. Para o homem grego a educação era a forma como a comunidade humana conservava e transmitia sua existência social e espiritual, propagando sua história pelas gerações. Isso era possível por meio de organizações físicas e espirituais, no caso, a educação. Essa era uma vontade consciente e racional, que podia transformar a natureza física do ser e a descoberta de si próprio - espírito humano.

Jaeger ainda destaca (2001) que a educação grega, sendo observada como um esforço consciente, não era uma propriedade individual e sim coletiva, de uma comunidade. A educação compartilhava na vida e no crescimento da sociedade, proporcionando um desenvolvimento social dependente da consciência dos valores que regiam a vida humana, transformando os valores válidos para cada sociedade.

Na Grécia, a formação do homem grego era o centro. Segundo Jaeger (2001, p. 7) era "[...] a formação de um elevado tipo de Homem. A ideia de educação representava para ele o sentido de todo o esforço humano". Os gregos viam a conexão viva, compreendendo que as partes formavam o todo, por isso não concebiam as partes isoladas do ser. A estrutura natural do ser, orgânica e originária, era formada pelo pensamento, pela linguagem, pelas 
ações e pela arte. Artista e pensador, o homem exemplar era considerado o ser político, que estava sempre a serviço da comunidade.

[...] os grandes homens da Grécia não se manifestam como profetas de Deus, mas antes como mestres independentes do povo e formadores dos seus ideais. Mesmo quando falam em forma de inspiração religiosa, esta assenta no conhecimento e formação pessoal. Mas por mais pessoal que esta obra do espírito seja, na sua forma e nos seus propósitos, é considerada pelos seus autores, com vigor infatigável, uma função social (JAEGER, 2001, p. 17).

Os verdadeiros representantes da Paidéia eram os detentores da palavra, ou seja, os poetas, músicos, filósofos, retóricos, oradores e os homens de Estado (JAEGER, 2001).

Giovanni Reale e Dario Antiseri (1990) trazem em sua obra História da Filosofia: Antiguidade e Idade Média, um breve histórico do declínio da ciência helenística. Com o incêndio ocasionado na Biblioteca de Alexandria e o domínio do Império Romano, Roma tornou-se o novo centro e a província de Alexandria, deixou de desempenhar o papel que possuía na época helenística. Conforme Jaeger (2001), a vitalidade do pensamento grego e da sua origem ou fonte espiritual é o motivo por regressarmos para a história da Grécia, pois muito mais do que apresentar um sentido antropológico, é uma história que une o espírito vivo e ativo de uma comunidade.

Para Foucault (2012), na genealogia é possível marcar as singularidades dos acontecimentos na história, observando os acasos sem o objetivo de realizar uma trajetória linear. A produção de verdades acontece em cada sociedade por meio de estratégias e técnicas sancionadas por dispositivos e mecanismos que estabelecem o que é certo ou errado, o que é verdadeiro ou falso nas relações de micropoderes. $\mathrm{O}$ pensamento grego e a escola na Grécia Antiga permitem uma reflexão sobre como a educação 
acontecia e se constituía na época, remetendo à constituição do sujeito em novos contextos.

Tendo lançado o olhar ao período clássico, vamos pensar sobre a escola da idade média e a criança no contexto escolar.

\section{A Escola desde a Idade Média e a Criança no Contexto Escolar: Interlocuções}

Ao longo dos séculos, com as mudanças ocorridas na sociedade em seus aspectos econômicos, políticos e sociais, a família passou também por transformações incorporando inclusive alterações naquele que teria sido seu papel durante séculos - gerar, cuidar e educar as crianças. Essas transformações são perceptíveis em relação à mudança da concepção de infância e da criança em cada contexto. Para melhor compreensão das suas diferentes concepções, torna-se relevante considerar dentre outros, o contexto histórico e social ao qual a criança estava inserida.

A mudança da concepção de infância foi compreendida como sendo eco da própria mudança nas formas de organização da sociedade, das relações de trabalho, das atividades realizadas e dos tipos de inserção que nessa sociedade têm as crianças. Assim, entendida a questão, não se trata de estudar a criança como um problema em si, mas compreendê-la segundo uma perspectiva histórica (KRAMER; LEITE, 1996, p. 19).

Esta análise, de acordo com Kramer e Leite (1996) está embasada numa concepção vygotskiana, que considera o sujeito como um ser social, histórico, político e cultural. Por isso, ao se tentar compreender as questões afetas à criança é necessário considerar este contexto.

A Idade Média, para Ariès (1981), foi uma época na qual os padres, legistas e moralistas influenciaram o sentimento moderno em relação à 
escola e à infância. O sentimento de paparicação e de fraqueza em relação à criança passou a direcionar o olhar para a sua formação moral e educativa.

$\mathrm{Na}$ época não haviam referências em relação às idades dos alunos ou distinção da criança e do adulto na escola, sendo que era permitido os adultos frequentarem os auditórios infantis caso desejassem aprender. No século XIII, as escolas serviam como asilos para estudantes da classe pobre e seu objetivo não era exclusivamente o de ensinar de modo escolar. Existia um sistema de camaradagem que podia se apresentar de diferentes modos: um pequeno estudante seguir um mais velho; se dirigir para internatos ou para morar com outra família por meio de contratos de aprendizagem - as crianças, adolescentes e adultos viviam na casa do mestre, ou na casa de um padre ou cônego, ou nas instituições escolares - que controlavam a frequência escolar; ou frequentavam a escola morando com sua própria família (ARIÈs, 1981).

As idades eram misturadas nos dormitórios, comportando desde crianças a idosos. Nas classes as idades também ficavam misturadas e atendiam um número exorbitante de alunos nos auditórios - superior a 200. As escolas não possuíam acomodações adequadas às crianças e demais alunos. Os alunos se sentavam em palhas até o século XVI, quando começaram a usar bancos (ARIÈS, 1981).

No século XV, segundo Ariés (1981), com o crescente número de alunos, as escolas foram se transformando em institutos de ensino. Inspirados nos princípios dominicanos e franciscanos, o objetivo desses locais era educar a infância e a juventude, protegendo a moralidade dos estudantes diante das tentações da vida. Os alunos eram separados da sociedade. Nessa época se estabeleceu nas escolas um sistema mais disciplinar, hierárquico e autoritário, que se baseava por meio de vigilância constante e aplicação de castigos corporais. Não se distinguia a forma de aplicação dos castigos entre as crianças, assim todas eram penalizadas. Também diminuiu a distinção entre criança e adolescência, pois ambos eram submetidos a castigos disciplinares. Essa se tornou uma nova atitude diante 
da infância. Os adultos de camadas mais pobres sofriam mais castigos do que os burgueses e nobres.

No período medieval (ARIÈS, 1981), o professor não se interessava em como seus alunos agiam e viviam fora da sala de aula. Para os mestres, os estudantes, em especial as crianças e jovens, precisavam de limites, disciplina, de serem educados moralmente, formar seus espíritos e adquirir conhecimentos. A infância era vista como fraca que necessitava de correção e punição para sua alma ser salva.

Em meados do século XV e início do século XVI (ARIÈS, 1981), os grupos começaram a ser divididos por idade e por grau de desenvolvimento para adaptar o ensino de cada mestre ao nível da classe. Esses grupos eram dirigidos por um docente formado por clérigos letrados. Entretanto, devido ao crescimento numeroso de estudantes, incluiu-se no corpo docente leigos, nobres e burgueses. Assim, deu-se início à estrutura de classe escolar moderna.

Os educadores do século XVI e XVII, formados por pensadores e moralistas eclesiásticos e governamentais (ARIÈS, 1981), ao perceberem que as crianças escolares eram comparadas a mendigos e criados, passaram a considerar a necessidade de criar uma visão de criança escolar como criança bem educada. A menção da criança bem educada se referia ao pequenoburguês na França ou ao gentleman da Inglaterra, que se distinguiria das crianças das camadas populares vistas como rudes e imorais.

Até metade do século XVII crianças com sete anos de idade podiam frequentar a escola, porém, diante da repugnância à precocidade e por considerarem as crianças pequenas como sujeitos incapazes e imbecis, apenas as crianças acima de 10 anos poderiam entrar na instituição escolar. Se estabelecia assim a primeira infância compreendendo crianças de até 10 anos, que frequentavam pequenas escolas, e uma infância escolar que atendia a partir de 10 anos de idade, prolongando, portanto, a infância dos escolares (ARIÈS, 1981). Apenas sujeitos do sexo masculino podiam frequentar a escola. As meninas eram educadas como adultas desde cedo - 
entre 10 a 14 anos de idade - para se casarem e serem mães de família ou escolherem a vocação e instrução religiosa, mal sabendo ler e escrever.

Nos séculos XVII e XVIII ainda existiam idades misturadas nas classes. Comenius (2006, p. 33), um importante educador do século XVII, era contra os castigos corporais e dizia que “[...] os açoites e as pancadas não têm nenhuma força para inspirar nos espíritos o amor das letras, mas, ao contrário, têm muito força para gerar na alma o tédio e a aversão contra eles”. Os castigos corporais foram se extinguindo devido à crescente reprovação da opinião pública diante do sistema disciplinar nas escolas abolição do uso do chicote.

Nesta mesma época, era possível perceber uma distinção social nas escolas ofertadas, dividindo-se em um ensino primário destinado ao povo aos pobres - e uma educação secundária com maior duração para a burguesia e aristocracia - ricos (ARIÈS, 1981). Essa diferença se dava pela preocupação da burguesia em conservar o trabalho braçal. Influenciados pelo pensamento Iluminista, os homens da sociedade da época limitavam "[...] a uma única classe social o privilégio do ensino longo e clássico, e condenar o povo a um ensino inferior, exclusivamente prático" (ARIÈS, 1981, p. 128).

Comenius (2006), em seu tratado sistemático de pedagogia, A Didáctica Magna, defendia que era possível ensinar a todos, não importasse o gênero, deficiência ou idade. Para ele, considerado o pai da pedagogia moderna, em cada fase se poderia aprender coisas diferentes e de maneiras diferentes. De acordo com Comenius (2006, p. 34), “[...] devem ser enviados às escolas, não apenas os filhos dos ricos ou dos cidadãos principais, mas todos por igual, nobres e plebeus, ricos e pobres, rapazes e raparigas, em todas as cidades, vilas, aldeias e casais isolados".

Em A polícia das famílias, o francês Jacques Donzelot fez um estudo do desenvolvimento da sociedade ocidental nos séculos XVIII e XIX e a transformação do conceito de família nesse período. Segundo Donzelot (1980), foram instituídos dispositivos compensatórios que contribuíram para 
a mutação das famílias e, então, do social. Pelo seu método genealógico, funcional e estratégico, o autor retratou um mapa da sociedade, trazendo a família com suas pequenas linhagens e mutações e seus efeitos no mundo social .

Donzelot (1980) enfatizou que uma linhagem pura ou de mutação da família pode iniciar por um desvio, iniciada com um ataque aos criados e amas, que o autor chama de linha baixa. Retratou sobre como a crítica aos ricos e pobres é diferente: pessoas pobres são vistas como vítimas da economia pública defeituosa e, portanto, abandonam seus filhos e o campo; quanto aos ricos, estes são obrigados a deixar seus filhos para outros cuidarem e educarem.

Uma segunda linha, de acordo com o autor, seriam os valores conjugais. Cita a preparação para o casamento como foco, não havendo a mesma preocupação na preservação da família. Donzelot (1980) também trouxe a diferença entre o papel da mulher pobre e da mulher rica no casamento - a primeira precisava oferecer dotes ou trabalhos domésticos, já a segunda estava direcionada à reprodução e consumo de adereços. A terceira linha é a filantrópica, com o divórcio, salientando à poupança e o investimento privado como mais um dispositivo compensatório.

A quarta linha conduziu para uma aliança entre a medicina e o Estado (DONZELOT, 1980). A higiene se tornou responsabilidade do setor público, enquanto a psiquiatria ficou com o setor privado. De maneira conjunto a medicina e o Estado fazem um trabalho de higienização que automaticamente modificam as famílias. Como última linha, a industrial, Donzelot (1980) encaminhou para a psicanálise, que se situou no meio híbrido dos setores público e privado. A psicanálise, ao perceber a ausência de equivalência entre o Estado e a psiquiatria, elaborou conceitos teóricos e práticos, construindo um sistema de flutuação. Psicanálise foi, segundo Donzelot, mais um mecanismo criado para a regulação da sociedade.

Para Donzelot (1980), a sociedade nasce de um sistema de flutuação e vive por meio de mecanismos reguladores e corretivos. Em meados do século 
XVIII, as primeiras literaturas ocidentais referentes às crianças, foram produzidas por médicos, administradores e militares. Eles destacavam a conservação das crianças e formas de serem educadas em sua época.

Para Ariès (1981, p. 124), com os jesuítas, oratorianos e jansenistas, surgiu o "[...] sentido da particularidade infantil, o conhecimento da psicologia infantil e a preocupação com um método adaptado a essa psicologia". Segundo Kant (2012), nascido no século XVIII, a educação compreendia os cuidados, a disciplina, a instrução e a formação. A disciplina preserva a humanidade removendo o elemento selvagem do homem, submetendo-o às leis da humanidade (KANT, 2012). Essa seria a parte negativa da educação; já a instrução seria a parte positiva.

De acordo com Kant (2012), desde a infância a disciplina necessita ser usada com o objetivo de colocar limites. Eles são necessários, pois caso contrário, as crianças terão atitudes de impor suas ideias, não respeitando os outros ao seu redor. Quando adulto, torna-se mais difícil colocar limites, portanto eles são necessários na formação do ser para a melhor convivência social. Como o autor dizia: "O homem só se pode tornar homem através da educação" (KANT, 2012, p. 12). E é pela educação que "[...] a natureza humana se desenvolverá cada vez melhor [...]" (KANT, 2012, p. 13).

Para Comenius (2006) a educação deveria ser iniciada na primeira infância por meio de recursos audiovisuais, pois na fase adulta ela seria mais difícil de ser concretizada. Trouxe como proposta dividir em quatro tipos de escola, abrangendo idades diferentes: infância - até os seis anos de idade; puerícia - dos seis aos 12 anos, fase de aprendizagem da língua nacional e preocupando-se em despertar o interesse dos alunos; adolescência - dos 12 aos 18 anos com o ensino do latim; e a juventude - dos 18 aos 24 anos com a orientação profissional.

A adolescência começou a se distinguir da infância no final do século XVIII e no século XIX por meio do alistamento para o serviço militar. Anteriormente (ARIÈS, 1981), quando não frequentavam a escola, crianças e jovens entre 11 a 18 anos entravam para o serviço militar. A partir do 
século XVIII só era permitido entrar no serviço militar aqueles que passaram na escola e depois se submetiam a escolas militares específicas.

Conforme Donzelot (1980), a imagem da infância mudou no século XVIII por nova reorganização dos comportamentos educativos por dois meios: difusão da medicina do mestiça - vigilância dos pais sobre os serviçais aos quais eram encarregados de cuidar de seus filhos; economia social pelo controle da reprodução de serviçais no meio urbano; e filantropia (caridade, generosidade).

No final do século XVIII e XIX, surgiram literaturas médicas sobre a criação, educação, medicação das crianças burguesas, dicionários de higiene, assim como sobre a arte de cuidados para as crianças da primeira infância (DONZELOT, 1980). Mais precisamente, no século XVIII os tratados médicos traziam doutrinas e conselhos para a educação das crianças burguesas. No século XIX esses conselhos tornaram-se imperativos. Segundo o autor, depois de Lavoisier, mudou-se a concepção de conexão entre medicina e moral educativa, separando a higienização da difusão de um saber. Diante do crescimento de médicos não qualificados na cidades, surgiram médicos de família.

Os médicos de família formaram uma aliança com as mães burguesas, atribuindo a elas a execução das normas, ensinando as mulheres a serem enfermeiras domésticas, colocando a medicina para o cuidado da saúde própria e não dos outros. "O médico prescreve, a mãe executa" (DONZELOT, 1980, p. 23). Essa ligação do médico com a família acaba por influenciar a reorganização da vida familiar, seja para não aceitar a educação exercida pelos serviçais que eram considerados os responsáveis pelo empobrecimento e promiscuidade social; seja pelo entendimento da importância educativa da mãe burguesa; ou seja para o menosprezo dos internatos religiosos (DONZELOT, 1980).

As famílias populares também se preocupavam com a higienização, mas diante de uma economia social, a produção dos efeitos era diferente dos resultantes das famílias burguesas. Tratava-se de vigiar diretamente as 
famílias populares, consideradas culpadas da promiscuidade e do empobrecimento urbano (DONZELOT, 1980). Para o autor, a família burguesa e a família operária dos séculos XVIII e XIX refletem nas famílias que conhecemos na atualidade. A família burguesa buscando retrair e controlar as camadas populares, mostrando o crescimento de seu poder; e a família popular operária, submetendo-se a vigiar seus próprios membros de tentações externas.

No século XIX (ARIÈS, 1981) uma nova concepção de educação foi sendo construída, trazendo a relevância de cuidar da criança e de desenvolver etapas para que ela tivesse suportes para se tornar um adulto responsável e com dignidade. Não cabia mais relacionar o sentimento da infância com a fraqueza. A escola se restringiria a atender apenas crianças e jovens, formando um ciclo escolar com duração de no mínimo quatro a cinco anos. Devido a propagação das universidades pela burguesia no final do século XIX, viu-se a necessidade de separar os escolares por idades, o que acarretou na dissipação da prática de manter alunos adultos ou mais velhos nas escolas.

O objetivo inicial da escola da Idade Média não era a educação da infância e dos estudantes, acolhendo todas as idades da vida, numa concepção humanista do Renascimento que confundia educação com cultura (ARIÊS, 1981). Não se privilegiava ou distinguia a infância. Com o passar dos séculos, de asilos as instituições se transformaram em espaços escolares objetivando preparar a infância e a juventude para a moralidade e aquisição de conhecimentos, para tornarem-se assim pessoas de bem. A escola que verificamos no final da Idade Média, modificou o sentimento de infância e nos transporta para a escola moderna que está presente ainda nos dias atuais.

Percebe-se que a educação, nos diferentes contextos, recebia funções específicas. Para Foucault (2012) não há uma evolução histórica, mas uma produção do sujeito de acordo com seu contexto, não sendo possível julgar as atitudes e pensamentos de cada época com o pensamento atual. É necessário 
se deslocar. Segundo Carvalho (2014), a multiplicação de aparelhos de normalização e técnicas de condução para a governamentalidade dos indivíduos, produziu saberes e comportamentos específicos para cada período da história, assim como verdades institucionalizadas impostas. Desta forma, uma produção de matrizes de comportamento fora intensificada no processo de massificação.

Conforme Carvalho (2014), a crítica é uma forma de insubmissão voluntária, contra a docilização e a domesticação impostas, indagando, questionando e interferindo para possíveis transformações. Para o autor, "criticar é engajar-se contra as formas de governo que dão azo à manutenção dos poderes institucionais" (CARVALHO, 2014, p. 116).

Ao realizar um breve apanhado histórico da educação desde a antiguidade ocidental, é possível realizar uma tomada de consciência. Conhecendo e compreendendo os antigos sistemas de educação, podemos refletir e buscar meios de escapar do determinismo histórico (MARROU, 1975).

Dussel (2017) considera que a escola moderna sempre foi um espaço precário e ela continua com algumas dessas características nos dias atuais, mesmo que com perspectivas e contextos diferentes. A situação econômica e social, presentes no capitalismo contemporâneo, são alguns dos causadores da precariedade por dificultar processos de subjetivação, quando apenas foca nas relações de contratação e reprodução de trabalho (DUSSEL, 2017).

A palavra precário deriva do latim precarius que possui como significado algo que é conseguido por súplica, dependendo do favor de outro, algo incerto (DUSSEL, 2017). A precariedade enfatiza, diante de sua raiz etimológica, o que o outro faz ou não faz. A autora analisa as condições atuais da escola e sua ligação com a precarização, propondo uma nova leitura da escola como ela é e sob quais condições a mesma deve continuar.

De acordo com Dussel (2017) discursiva, material e estratégica são as condições da perdurabilidade das montagens sociais que sustentam a escola como essa se encontra. A durabilidade discursiva perpetua o conhecimento 
codificado. Em meados do século XX, com a intenção de incluir e se organizar diante dos saberes e das necessidades populares, o ideal burocrático da escola de desviou de seu propósito inicial. Conforme Dussel (2017, p. 96),

[...] a escola, para sustentar-se como montagem, precisa de condições discursivas que afirmem a sua importância e a sua centralidade para a transmissão da cultura; sem essa legitimidade, o que realiza tem poucas chances de perdurar.

A escola é uma montagem social que não se define apenas pela sua estrutura física, como também pelas operações que a constrói. Segundo Dussel (2017), a escola é um espaço que está em movimento e se responsabiliza pela produção de cidadãos e cidadãs (DUSSEL, 2017).

A instituição escolar passou por contratempos ao tentar se recriar diante das novas condições sem perder suas particularidades, com o propósito de tentar manter sua existência. Para Dussel (2017), a organização da escola não pode ter características imediatas como os novos modelos de consumo capitalista estabelecem. É preciso dar condições para que a escola perdure, pensando e refletindo sobre o que se pode fazer diante das transformações da sociedade. A transmissão de conteúdos de forma descontextualizada não mostra ser mais cabível no espaço escolar para sua perdurabilidade.

Um dos elementos necessários destacado por Dussel (2017) é o fortalecimento das condições discursivas, questionando quais formas seriam possíveis para que a escola atue como espaço de igualdade. Também é necessário considerar tanto quais como os porquês de utilizar certas condições estratégicas e materiais, de disposição e organização escolar e pensar em maneiras de focalizar os saberes, os conhecimentos.

\section{Considerações Finais}


Foucault (2012) em Microfísica do Poder, nos faz pensar sobre a institucionalização dos saberes e como podemos resistir a essas imposições. A escola tem importante papel no desenvolvimento humano e, conforme Carvalho (2014), a instituição escolar precisa pensar e repensar estratégias visando modificações nas relações de forças, numa arte de desgovernar.

Esta breve trajetória da escola remete a pensar sobre os diferentes contextos históricos e influências que a educação, oriunda desses períodos, faz perdurar hodiernamente. Leva a questionar as autoridades, as referências sociais e as organizações que estão estabelecidas, assim como pensar a criança no espaço escolar nos diversos contextos.

Precarizar a escola (DUSSEL, 2017) é uma maneira de evidenciar e criticar as imposições e as formas de exclusão para desestruturá-la, transformando-a num espaço dinâmico e questionando sua configuração, sua organização. O pensamento de Foucault (2012; 2016), também trazido por Carvalho (2014), provoca uma reflexão sobre como a institucionalização precisa de desinstitucionalizar, pensando em estratégias para transformar as relações de poder e saber, em um movimento de contra poder, considerando os sujeitos que nela estão inseridos.

\section{Referências}

ARAÚJO, Inês Lacerda. Foucault e a crítica do sujeito. Curitiba: Editora UFPR, 2000.

ARIÈS, Philippe. História social da criança e da família. Trad. Dora Flaksman. 2. ed. Rio de Janeiro: LTC Editora, 1981.

CARVALHO, Alexandre Filordi de. Foucault e a crítica à institucionalização da Educação: implicações para as artes de governo. Pro-Posições, v. 25, n. 2 (74), p. 103-120, maio/ago. 2014, Disponível em: http://www.scielo.br/pdf/pp/v25n2/06.pdf. Acesso em: 23 maio 2019.

CHÂTELET, François. Uma história da razão: entrevistas com Émile Noel. Trad. Lucy Magalhães. Rio de Janeiro: Jorge Zahar, 1994. 
COMENIUS, Iohannis Amos. Didactica magna. 3. ed. São Paulo: Martins Fontes, 2006.

DONZELOT, Jacques. A polícia das famílias. Trad. M. T. Da Costa Albuquerque. Rio de Janeiro: Edições Graal, 1980.

DUSSEL, Inés. Sobre a precariedade da escola. In: LARROSA, Jorge (org.). Elogio da escola. Trad. Fernando Coelho. Beolo Horizonte: Autêntica, 2017. p. 87-111.

FOUCAULT, Michel. As palavras e as coisas: uma arqueologia das ciências humanas. Trad. Salma Tannus Muchail. 10 ed. São Paulo: Martins Editora, 2016. 2012. Microfísica do poder. Trad. Roberto Machado. 25. ed. São Paulo: Graal,

HALL, Jonathan Mark. Quem eram os gregos. Revista do Museu de Arqueologia e Etnologia. São Paulo, 11: 213-225, 2001. Disponível em: www.revistas.usp.br > revmae > article > download. Acesso em: 05 dez. 2019.

JAEGER, Werner Wilhelm. Paidéia: a formação do homem grego. Trad. Artur M. Parreira. 4. ed. São Paulo: Martins Fontes, 2001.

KANT, Immanuel. Sobre a pedagogia. Trad. João Tiago Proença. Lisboa: Edições 70, Ltda, 2012.

KRAMER, Sonia; LEITE, Maria Isabel (orgs.). Infância: fios e desafios da pesquisa. 7. Ed. Campinas, São Paulo: Papirus, 1996.

MARROU, Henri Irenée. História da educação na antiguidade. Trad. Mário Leônidas Casanova. São Paulo: Editora Pedagógica e Universitária Ltda, 1975.

PLATÃO. O Banquete. In: PLATÃO. Coleção os Pensadores. São Paulo: Nova Cultural, 1991.

REALE, Giovanni; ANTISERI, Dario. A ciência antiga na época imperial. In: . História da filosofia: antiguidade e idade média. São Paulo: Paulus, 1990. p. 356-368, 